\title{
Perfil e intervenção fisioterapêutica dos pacientes vítimas de trauma admitidos na unidade de urgência e emergência em um Hospital Universitário do Oeste do Paraná
}

\author{
Profile and physiotherapeutic intervention of patients victims of trauma admitted to the urgent and
} emergency unit of a University Hospital in West Paraná

Perfil e intervención fisioterapéutica de pacientes víctimas de trauma ingresados en la unidad de urgencias y emergencias de un Hospital Universitario de Paraná Occidental

\section{Resumo}

Objetivos: Caracterizar o perfil das vítimas de traumas internados na sala de emergência de um Hospital Universitário do Oeste do Paraná e fazer o levantamento dos casos de trauma atendidos pelo serviço de fisioterapia, bem como as principais abordagens e condutas prestadas. Metodologia: Pesquisa observacional, retrospectiva, transversal e de caráter quantitativo, realizada através das informações dos prontuários. A amostra foi coletada através de levantamento dos pacientes que deram entrada na sala de emergência, totalizando 1.020 prontuários. A coleta de dados foi realizada no período de um ano. A análise foi realizada através de estatística descritiva simples. Resultados: Foram analisados os 1.020 prontuários, onde 17 foram excluídos por não serem efetivamente admitidos na sala de emergência. A amostra total do trabalho foi 297 prontuários, no qual a maioria é do sexo masculino com idade média de 40,26 $\pm 17,48$ anos. A principal causa de internação dos politraumas foi devido a traumatismo cranioencefálico. 185 pacientes necessitaram de ventilação mecânica invasiva. Quanto ao desfecho final dos pacientes, somente 55 foram a óbito. Receberam atendimento fisioterapêutico 254 pacientes. Conclusão: Os principais casos de pacientes politraumatizados foram do sexo masculino, com maior prevalência no diagnóstico de Trauma Cranioencefálico, seja isolado ou associado a outros traumas. Quanto ao desfecho final, maioria teve uma evolução satisfatória, indo de alta hospitalar. Em relação a fisioterapia, pelo número elevado de pacientes politraumatizados com necessidade de ventilação mecânica, destaca-se condutas com ênfase na fisioterapia respiratória.

Palavras-chave: Traumatismo múltiplo; Traumatismos craniocerebrais; Fisioterapia; Serviços de atendimento de emergência.

\begin{abstract}
Objectives: To characterize the profile of trauma victims admitted to the emergency room of a University Hospital in the West of Paraná and to survey the trauma cases treated by the physiotherapy service, as well as the main approaches and conduct provided. Methodology: Observational, retrospective, cross-sectional and quantitative research, carried out using information from medical records. The sample was collected through a survey of patients who were admitted to the emergency room, totaling 1,020 medical records. Data collection was carried out over a period of one year. The analysis was performed using simple descriptive statistics. Results: The 1,020 medical records were analyzed, of which 17 were excluded because they were not effectively admitted to the emergency room. The total sample of the work consisted of 297 medical records, most of which are male and with a mean age of $40.26 \pm$ 17.48 years. The main cause of hospitalization for multiple trauma was due to traumatic brain injury. 185 patients required invasive mechanical ventilation. As for the final outcome of the patients, only 55 died. 254 patients received
\end{abstract}


physical therapy care. Conclusion: The main cases of multiple trauma patients were male, with a higher prevalence in the diagnosis of Traumatic Brain Injury, either isolated or associated with other traumas. As for the final outcome, most had a satisfactory evolution going from hospital discharge. In relation to physiotherapy, due to the high number of polytraumatized patients requiring mechanical ventilation, there is an emphasis on conducts with an emphasis on respiratory physiotherapy.

Keywords: Multiple trauma; Craniocerebral trauma; Physiotherapy; Emergency medical services.

\section{Resumen}

Objetivos: Caracterizar el perfil de las víctimas de trauma ingresadas en el servicio de urgencias de un Hospital Universitario del Oeste de Paraná y relevar los casos de trauma atendidos por el servicio de fisioterapia, así como los principales abordajes y conductas proporcionados. Metodología: Investigación observacional, retrospectiva, transversal y cuantitativa, realizada con información de historias clínicas. La muestra fue recolectada a través de una encuesta a los pacientes que ingresaron al servicio de urgencias, totalizando 1.020 historias clínicas. La recolección de datos se llevó a cabo durante un período de un año. El análisis se realizó mediante estadística descriptiva simple. Resultados: Se analizaron las 1.020 historias clínicas, de las cuales se excluyeron 17 por no estar efectivamente internados en urgencias. La muestra total del trabajo estuvo constituida por 297 historias clínicas, siendo la mayoría de sexo masculino y con una edad media de 40,26 \pm 17,48 años. La principal causa de hospitalización por politraumatismo fue por traumatismo craneoencefálico. 185 pacientes requirieron ventilación mecánica invasiva. En cuanto al desenlace final de los pacientes, solo 55 fallecieron. 254 pacientes recibieron atención de fisioterapia. Conclusión: Los principales casos de politraumatizados fueron del sexo masculino, con mayor prevalencia en el diagnóstico de Traumatismo Craneoencefálico, ya sea aislado o asociado a otros traumatismos. En cuanto al resultado final, la mayoría tuvo una evolución satisfactoria desde el alta hospitalaria. En relación a la fisioterapia, debido al elevado número de pacientes politraumatizados que requieren ventilación mecánica, se destacan las conductas con énfasis en la fisioterapia respiratoria.

Palabras clave: Trauma múltiple; Traumatismos craneocerebrales; Fisioterapia; Servicios médicos de urgencia.

\section{Introdução}

Segundo a Organização Mundial da Saúde (OMS), nos últimos anos os traumas vêm aumentando sua incidência, sendo considerados a doença do século e por muitas vezes negligenciados pela sociedade. Estimativas apontam que, em média, são gastos anualmente cerca de $\mathrm{R} \$ 10$ bilhões nos casos de acidentes em áreas urbanas e $\mathrm{R} \$ 40$ bilhões com acidentes rodoviários, desta forma são gerados altos custos para o Sistema Único de Saúde (SUS) bem como para os hospitais (Ministério da Saúde, 2019).

O Sistema Único de Saúde (SUS) é essencial nos atendimentos e assistência à saúde, estes serviços vêm aumentando gradualmente em decorrência ao aumento da violência urbana, do número de acidentes e da falta de assistência básica à saúde em vários locais, constituindo-se assim, como um importante componente da assistência à saúde (Paixão et al., 2015). Pelo aumento da demanda nos últimos tempos, as unidades de urgência e emergência hospitalares, por muitas vezes, acabam atuando acima da sua capacidade total causando uma sobrecarga tanto do sistema de saúde, quanto da equipe assistencial (Sousa et al., 2019).

O Hospital Universitário do Oeste do Paraná - HUOP, atende a população em geral com 100\% dos seus leitos destinados ao Sistema Único de Saúde (SUS), abrangendo aproximadamente 2 milhões de habitantes e prestando atendimentos em diversas áreas clínicas, conta com uma unidade de Pronto Socorro, contendo 3 leitos de estabilização (podendo chegar a um número maior de leitos em situações especiais), onde os pacientes permanecem até conseguir uma vaga na Unidade de Terapia Intensiva (UTI) ou na enfermaria. Além disso o HUOP abrange 25 municípios da 10ª Regional de Saúde e mais 4 Regionais de Saúde do estado do Paraná e é referência na assistência à traumas, cirurgias vasculares e neurologia, prestando atendimento aos pacientes que necessitam de alta complexidade (Universidade Estadual do Oeste do Paraná, 2020).

O número de pacientes traumáticos que necessitam de suporte nas unidades de urgência e emergência no Brasil, nos últimos anos vem aumentando de forma desordenada, chegando à 91,8\%, isso significa que o número quase dobrou passando de 17,1/100.000 habitantes em 1998 para 32,8/100.000 habitantes em 2015. No ano de 2012 os principais casos registrados foram de jovens do sexo masculino na faixa etária de 15 a 29 anos, e no período de 2000 e 2014 no Brasil, o número de óbitos 
causado por acidentes traumáticos, aumentou de 28.995 para 43.780. Isso ocorre devido ao aumento da violência urbana e dos acidentes de trânsito, desta forma é considerado imprescindível a necessidade da organização hospitalar na assistência ao trauma, desenvolvendo programas especializados, com suporte necessário no atendimento dos pacientes durantes todo o período de hospitalização (Lentsck et al., 2019).

Pelo fato dos acidentes de caráter traumático serem considerados os principais causadores de lesões graves, e consequentemente os que mais evoluem a óbito, ficando atrás somente das doenças de causas cardiovasculares, os cuidados da equipe multidisciplinar são indispensáveis, auxiliando com intervenções necessárias no intuito de reduzir as sequelas incapacitantes, auxiliando na recuperação e prevenção das complicações e visando o retorno às atividades diárias (Will et al., 2020). Ressalta-se também a predominância dos casos em pacientes jovens, reduzindo assim a expectativa de vida para 35 anos, constituindo-se em muitos países como um dos principais problemas da saúde pública (Ministério da Saúde, 2015, Silva et al., 2014).

Inúmeros são os fatores causadores dos traumas. Por ano, cerca de 5,8 milhões de pessoas são vítimas de acidentes, o que representa $10 \%$ de todas as mortes. O trauma consiste nas alterações causadas no organismo com intensidades variadas, que podem ser provocadas por agentes físicos, químicos e/ou psíquicos, causando deformidades estruturais e/ou fisiológicas, podendo ocorrer se forma acidental ou alguns casos intencionais (Azevedo, 2021). Sendo resultante de várias formas de energia ou até de fatores externos como: quedas, acidente de trabalho ou automobilístico, ferimento por arma de fogo ou arma branca ou até mesmo de agressão física (Ministério da Saúde, 2013; Schossler, 2019).

Normalmente esses pacientes evoluem com outras complicações, dependendo da gravidade das lesões, da idade e de comorbidades associadas, podendo desenvolver complicações como sepse, pneumonia, infecções na ferida operatória ou no trato urinário. Isso se dá pelo tempo prolongado de internação, pelo uso de ventilação mecânica, pela incapacidade funcional e pelas limitações decorrentes do acidente. Desta forma os pacientes politraumatizados contribuem no aumento da morbidade e mortalidade. Os casos mais comuns admitidos no pronto socorro são os de traumatismo cranioencefálico (TCE), seguido pelo trauma torácico (Gomes et al., 2018).

$\mathrm{O}$ alto índice de mortalidade ocorre devido as lesões que esses traumas geram ao organismo e principalmente pelo fato de uma assistência inadequada. Com um atendimento de qualidade, prestando todo o auxílio necessário no momento da emergência sem que ocorra atrasos, consegue-se minimizar os riscos e melhorar os resultados, além de reduzir as sequelas posteriores e o número de óbito (Araujo \& Araujo 2020; Machado et al., 2018).

Na urgência e emergência, a inserção do fisioterapeuta ainda é algo novo, mas que vem se tornando indispensável, principalmente pelo número elevado de pacientes que necessitam do uso de oxigenioterapia e de ventilação mecânica, e pelos frequentes casos de alterações cardiopulmonares que necessitam de uma maior assistência. Sendo assim, esse profissional atua diretamente na reabilitação precoce destes pacientes, favorecendo as condutas e auxiliando na diminuição do tempo de permanência na emergência (Almeida et al., 2017; Moura et al., 2018).

A Fisioterapia também atua como uma grande aliada na minimização das sequelas recorrentes aos traumas, atuando na reabilitação destes pacientes desde sua admissão na emergência. Além disso, esse profissional preconiza pela humanização nos atendimentos, proporcionado a reorganização dos padrões de saúde e da atenção primaria. Atualmente umas das dificuldades encontradas por esses profissionais é quanto a falta de consciência da equipe sobre as competências que cabem ao fisioterapeuta na urgência e emergência. Porém, de acordo com investigações e atuação do mesmo, vem ganhando espaço pelos benefícios que proporcionam aos pacientes (Padovani et al., 2017; Werle et al., 2019).

O presente estudo objetivou-se a caracterizar o perfil dos pacientes vítimas de traumas internados na sala de emergência de um Hospital Universitário do Oeste do Paraná e fazer o levantamento dos casos de trauma atendidos pelo serviço de fisioterapia, bem como as principais abordagens e condutas prestadas pelo mesmo, com o intuito de acrescer dados 
aos estudos nacionais a respeito do perfil de pacientes politraumatizados atendidos em serviços de urgência e emergência do Sistema Único de Saúde, assim como subsidiar a relevância da atuação do profissional fisioterapeuta neste contexto.

\section{Metodologia}

Trata-se se uma pesquisa observacional, transversal, documental e de caráter quantitativo (Vieira \& Hossne, 2021), onde a busca foi realizada através das informações presentes nos prontuários disponíveis no software de gestão TasyRel. A amostra foi coletada através de levantamento dos pacientes que deram entrada na sala de emergência do Hospital Universitário do Oeste do Paraná - HUOP. A coleta de dados foi realizada no período de dia 01 de janeiro de 2020 até 31 de dezembro de 2020.

Os critérios de inclusão estabelecidos nesta pesquisa foram pacientes internados na sala de emergência com diagnóstico inicial de origem traumática, sendo este o motivo que levou ao internamento, de ambos os sexos e sem limite de idade. E como critério de exclusão, pacientes com diagnóstico inicial de doenças não traumáticas ou pacientes vítimas de trauma que não chegaram a ser admitidos na sala de emergência.

As informações coletadas dos prontuários dos pacientes foram as seguintes: dados sociodemográficos (idade, sexo e estado civil); dados relacionados ao atendimento/internamento na sala de emergência (diagnóstico inicial, necessidade de suporte de O2, uso de ventilação mecânica invasiva ou não invasiva, extubação, Parada Cardiorrespiratória - PCR, tempo de permanência e destino do paciente) e os dados sobre o atendimento fisioterapêutico (se atendido pelo serviço de fisioterapia, números de atendimentos e condutas gerais).

Os dados coletados foram processados e analisados pelo Programa de Software Microsoft ${ }^{\circledR}$ Excel 16.0. As variáveis do referido estudo passaram por análises descritivas simples, média, desvio padrão, frequência absoluta e relativa, e a pesquisa foi iniciada após ser aprovada pelo Comitê de Ética em pesquisa da Universidade Estadual do Oeste do Paraná - UNIOESTE, com número de CAAE: 40327020.9.0000.0107.

\section{Resultados e Discussão}

Foram analisados os 1.020 prontuários de pacientes selecionados pelo software de gestão TasyRel, admitidos na unidade de urgência emergência do HUOP no ano de 2020, porém 17 prontuários foram excluídos por não serem efetivamente admitidos na sala de emergência do hospital. A amostra total do trabalho foi de 297 (29,11\%) prontuários que se encaixaram nos critérios de inclusão definido pelo estudo, admitidos com diagnóstico inicial de causa traumática, no qual 235 (79,12\%) eram do sexo masculino e $62(20,88 \%)$ do sexo feminino, com idade média de 40,26 $\pm 17,48$ anos.

Os resultados do estudo apontam que o perfil dos pacientes vítimas de traumas são, em sua maioria, do sexo masculino, corroborando com os estudos de Silva et al. (2017) e Lentsck et at. (2019), que realizaram investigações quanto ao perfil epidemiológico em prontuários de pacientes traumatizados, encontrando maior prevalência nas admissões do sexo masculino, com 73,9\% e somente $26,1 \%$ do sexo feminino, juntamente com o estudo de Rezende et al. (2012), onde avaliaram os atendimentos prestado pelo Serviço de Atendimento Móvel de Urgência (SAMU) em pacientes politraumatizados e, das 4.541 vítimas, 2.915 eram do gênero masculino, indicando a predominância de ocorrência de traumas em homens.

Segundo estudo realizado por Gomes et al. (2017), os pacientes do sexo masculino se envolvem mais em eventos traumáticos, principalmente por motivos sociais, culturais e biológicos, podendo apresentar atitudes mais violentas, aumentando essa gravidade devido ao consumo de bebidas alcoólicas em eventos festivos. Já as pacientes do sexo feminino aparecem mais em internação devido a causas clínicas. Em relação à faixa etária, na pesquisa citada anteriormente, foram encontradas maior incidência em jovens com idade entre 25 a 44 anos com 30,6\% e em jovens adultos com idade entre 45 a 59 anos com 46,6\%, de acordo com os dados deste trabalho onde apresentou-se com uma média de idade de 40 anos. 
O motivo da internação foi classificado conforme o diagnóstico primário, evoluído pelo médico responsável nos prontuários. Portanto, as causas de internamento por trauma encontradas neste estudo foram os politraumas, em 124 pacientes (41,75\%), podendo alguns destes pacientes também apresentarem Traumatismo Cranioencefálico (TCE) associado ao(s)trauma(s) e 79 casos (26,60\%) foram vítimas somente de TCE (sem outros tipos de traumas associados). Além disso, outras causas de admissão foram devido a ferimentos por arma de fogo (FAF) em 32 pacientes (10,77\%), ferimentos por arma branca (FAB) em 23 pacientes (7,74\%), casos de intoxicação exógena em 22 pacientes (7,41\%), casos de enforcamento em 5 indivíduos $(1,68 \%)$ e 12 pacientes $(4,04 \%)$ vítimas de queimaduras, sendo 2 deles por descarga elétrica e os demais por explosão com fogo, conforme apresentado na Tabela 1.

Tabela 1. Descrição dos internamentos por origem traumática, admitidos na sala de emergência do hospital $(\mathrm{n}=297)$.

\begin{tabular}{lcc}
\hline Variáveis & $\mathbf{N}^{\mathbf{0}}$ & $\%$ \\
\hline Diagnóstico & & 41,75 \\
Politraumas (com ou sem TCE associado) & 124 & 26,60 \\
Traumatismo Cranioencefálico - TCE (somente) & 79 & 10,77 \\
Ferimento por Ama de Fogo -FAF & 32 & 5,72 \\
Ferimento por Arma Branca - FAB & 23 & 7,74 \\
Intoxicação exógena & 22 & 4,04 \\
Queimadura & 12 & 4,04 \\
Enforcamento & 5 & \\
\hline
\end{tabular}

Fonte: Autoria própria (2022).

Os pacientes politraumatizados $(n=124)$, foram os que apresentavam múltiplas lesões traumáticas, como traumas de membros ou toracoabdominais, associados ou não aos traumatismos cranioencefálicos e aos traumas de coluna, conforme descrito no Gráfico 1.

Gráfico 1. Pacientes politraumatizados admitidos na sala de emergência do hospital $(\mathrm{n}=124)$.

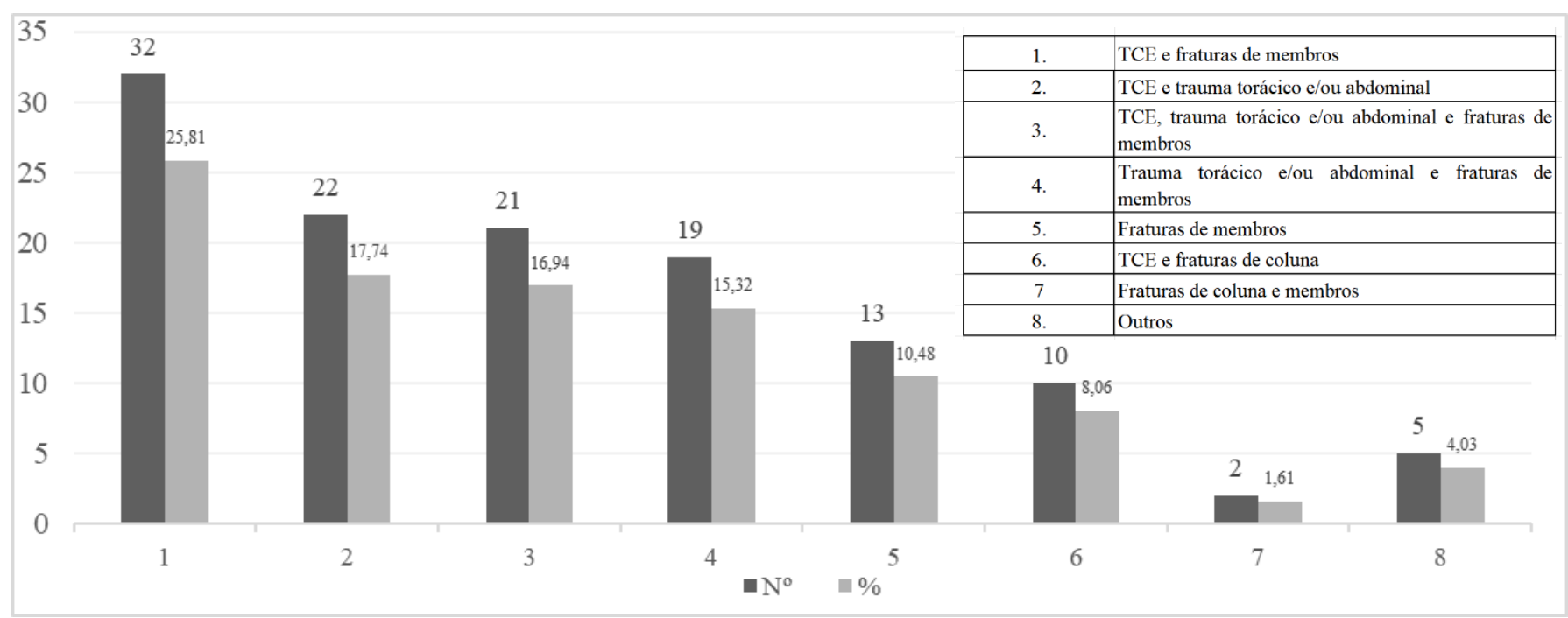

Fonte: Autoria própria (2022). 
O TCE foi o achado mais frequente, entre as vítimas de trauma do presente estudo, dado encontrado em 160 pacientes $(53,87 \%)$. Porém, como alguns pacientes possuíam outros traumas associados ao mesmo, optou-se em separar os dados deste estudo em pacientes com TCE associado a outros traumas e pacientes que apresentaram somente TCE (Gráfico 2).

Gráfico 2. Pacientes vítimas de TCE, admitidos na sala de emergência do hospital $(\mathrm{n}=160)$.

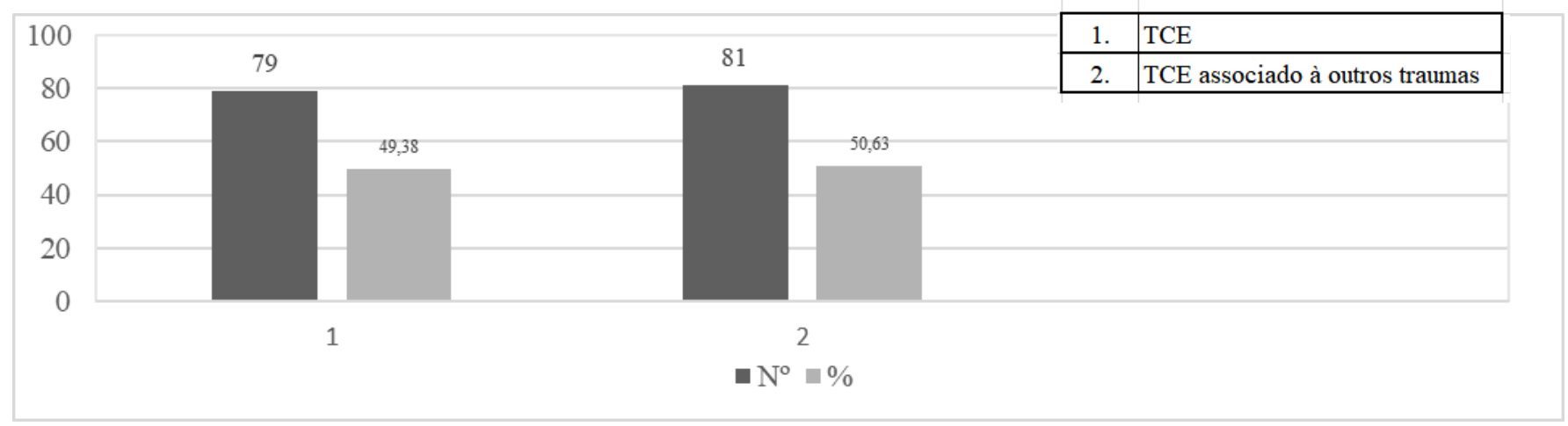

Fonte: Autoria própria (2022).

Segundo o estudo de Schossler (2019), a maior ocorrência foi de Traumatismo Cranioencefálico (TCE) com 35,5\% dos casos, TCE + fraturas em 30,6\% dos casos, TCE + politrauma em 8,1\% dos casos, fraturas + pneumotórax em 4,8\%, ferimento por arma de fogo em 3,2\%, TCE + pneumotórax em 1,6\%, TCE + trauma torácico em 1,6\%, ferimento por arma branca em 1,6\% e TCE + ferimento por arma de fogo em 1,6\% dos casos, corroborando com os resultados encontrado no presente estudo, em que também verificou-se que o TCE é a principal causa de internação por motivo traumático e que, na maioria dos casos, está associado também a outros traumas.

$\mathrm{Na}$ admissão de um paciente vítima de trauma, o principal intuito é minimizar ou excluir as possíveis sequelas decorrentes do trauma, sendo de extrema importância a abordagem inicial, ainda na unidade de urgência e emergência. Assim sendo, é primordial o conhecimento dos profissionais da equipe multidisciplinar, prestando o suporte necessário para os pacientes. Para Santos et al. (2021), os atendimentos prestados inicialmente ajudam a reduzir consideravelmente as complicações respiratórias, hemorrágicas e osteomusculares, que aumentam a probabilidade destes pacientes evoluírem clinicamente de forma desfavorável.

O serviço de Fisioterapia na unidade de urgência e emergência, desempenha papel importante seja na admissão, na transferência interna desses pacientes, e no acompanhamento, avaliando a necessidade de uso de oxigenioterapia suplementar e realizando a titulação da mesma, auxiliando a equipe multiprofissional na intubação orotraqueal, e realizando o manejo ventilatório, e a assistência diária, desempenhando condutas especificas para cada indivíduo de acordo com a necessidade.

No presente estudo, 82 pacientes $(27,61 \%)$ vítimas de trauma admitidos na sala de emergência, necessitaram de oxigenioterapia suplementar, ofertada em ventilação espontânea. A Tabela 2 representa os pacientes que já foram admitidos em uso de oxigênio suplementar e os que fizeram uso do mesmo posteriormente na sala de emergência, sendo este suporte ofertado em baixo ou alto fluxo. Os demais, 215 (73,39\%) pacientes, não fizeram uso oxigenioterapia ou já foram admitidos na sala de emergência em Ventilação Mecânica Invasiva (VMI).

Necessitaram de VMI 185 (62,29\%) pacientes, sendo que 141 (47,47\%) já foram admitidos em intubação orotraqueal (IOT) e $42(14,14 \%)$ pacientes necessitarem de intubação após a admissão na sala de emergência. Os demais, $112(37,71 \%)$ pacientes, não necessitaram de IOT durante o período de internação na sala de emergência.

Schossler (2019), pesquisando pacientes admitidos um uma unidade de urgência e emergência, observou que 25,9\% dos pacientes utilizaram oxigênio suplementar e 55,5\% necessitaram de intubação orotraqueal, dados semelhantes encontrados 
na presente pesquisa, o que demonstra que mais da metade dos pacientes politraumatizados evoluem para intubação orotraqueal, necessitando de suporte ventilatório.

Tabela 2. Uso de Oxigenioterapia, necessidade de IOT e VM ( $\mathrm{n}=297)$.

\begin{tabular}{lcc}
\hline Variáveis & $\mathbf{N}^{\mathbf{0}}$ & $\%$ \\
\hline Oxigenioterapia & 82 & 27,61 \\
Sim & 215 & 73,39 \\
Não & & \\
Intubação Orotraqueal (IOT) & 141 & 47,47 \\
Admitido com IOT & 42 & 14,14 \\
Necessitou de IOT na sala de emergência & 114 & 38,38 \\
Não necessitou de IOT na sala de emergência & & \\
Uso de Ventilação Mecânica Invasiva & 185 & 62,29 \\
Sim & 112 & 37,71 \\
Não & &
\end{tabular}

Fonte: Autoria própria (2022).

Destaca-se também os casos de pacientes que após a admissão apresentaram parada cardiorrespiratória na sala de emergência (conforme apresentado na Tabela 3), onde 18 deles $(6,06 \%)$ tiveram PCR com reanimação e $12(4,04 \%)$ casos apresentaram PCR sem reanimação devido prognóstico limitado. Dos 30 pacientes que apresentaram PCR, 10 (33,33\%) casos foram internados por TCE com trauma toracoabdominal e de membros, 8 (26,67\%) casos internados por TCE associado a trauma toracoabdominal, 7 (23,33\%) por TCE com fraturas em membros, $3(10 \%)$ devido à intoxicação exógena e $2(6,67 \%)$ casos em vítimas de queimaduras, o que sugere que vítimas de TCE associados a politraumatismos, principalmente com trauma toracoabdominal, podem corresponder a maior gravidade e risco de PCR.

Tabela 3. Pacientes que apresentaram PCR na sala de emergência $(n=297)$.

\begin{tabular}{lcc}
\hline Variáveis & $\mathbf{N}^{\mathbf{0}}$ & $\%$ \\
\hline Parada Cardiorrespiratória (PCR) na Sala de Emergência & 18 & 6,06 \\
Sim, com reanimação & 12 & 4,04 \\
Sim, sem reanimação & 269 & 89,90 \\
Não & \\
\hline
\end{tabular}

Fonte: Autoria própria (2022).

A sala de emergência é o local de entrada dos pacientes instáveis e posteriormente de estabilização, desta forma, esses pacientes permanecem por um período limitado até surgir vaga em leitos de Unidade de Terapia Intensiva (UTI), transferência para outros hospitais ou em casos de melhora do quadro clínico de alta para as alas de enfermarias.

Quanto ao destino do paciente após admissão e/ou estabilização na sala de emergência, 154 (51,85\%) foram encaminhados para a UTI do mesmo hospital, 110 pacientes $(37,04 \%)$ apresentaram melhora considerável do quadro clínico e tiveram alta da sala de emergência para a enfermaria do hospital, 11 indivíduos $(3,70 \%)$ foram transferidos para outros hospitais e 22 pacientes (7,14\%) evoluíram para óbito ainda na sala de emergência (Tabela 4).

Após a saída da sala de emergência e admissão em outros setores do hospital, 223 pacientes $(75,08 \%)$ apresentaram evolução satisfatória e tiveram alta hospitalar, $19(6,40 \%)$ pacientes foram transferidos para outros hospitais e 55 pacientes 
$(18,52 \%)$ não tiveram boa resposta clínica e evoluíram à óbito tardiamente, nas unidades em que estavam internados (Tabela $4)$.

Tabela 4. Destino e desfecho do paciente após a sala de emergência $(n=297)$.

\begin{tabular}{lcc}
\hline Variáveis & $\mathbf{N}^{\mathbf{0}}$ & $\mathbf{\%}$ \\
\hline Destino do paciente após saída da Sala de Emergência & & 51,85 \\
Transferido para UTI & 154 & 37,04 \\
Transferido para Enfermaria & 110 & 3,70 \\
Transferência de Hospital & 11 & 7,41 \\
Óbito (na sala de emergência) & 22 & 75,08 \\
Desfecho Hospitalar do Paciente & 223 & 6,40 \\
Alta melhorada & 19 & 18,52 \\
Transferência hospitalar & 55 & 25 \\
Óbito & & \\
\hline
\end{tabular}

Fonte: Autoria própria (2022).

No estudo realizado por Gonçalves (2019), a respeito do desfecho dos pacientes admitidos na sala de emergência, $11,42 \%$ deles evoluíram a óbito ainda na urgência e emergência, 10,47\% foram transferidos para outras unidades hospitalares e $5,71 \%$ tiveram alta hospitalar. O autor aponta também que, no caso das transferências internas dentro do hospital de origem, $39,04 \%$ foram transferidos para a UTI e 33,33\% transferidos para a enfermaria, corroborando com os dados encontrados na presente pesquisa, o que reforça a gravidade dos pacientes vítimas de traumas, pois a maioria requer internamento em unidade de cuidados intensivos.

Quanto ao diagnóstico clínico inicial que levou ao internamento, dos pacientes que evoluíram a óbitos durante a internação, conforme representado na Tabela 5, observou-se que os pacientes admitidos com trauma torácico e/ou abdominal isolado (a maioria vítima de FAB ou FAF) ou associado a TCE e/ou fraturas de membros ou coluna tiveram incidência maior de mortalidade. Corroborando com o estudo de Pimentel et al. (2015), que avaliou o óbito no trauma abdominal fechado com abordagem cirúrgica, em sua amostra total de 86 pacientes, 31 evoluíram a óbito (36\%), sendo que desses pacientes que evoluíram a óbito, 96\% tinham lesões extra-abdominais graves associadas (trauma crânio encefálico, trauma grave de tórax e fraturas). Desta forma pode-se ressaltar a importância de uma avaliação criteriosa nesses pacientes, bem como, do acompanhamento feito pela equipe multidisciplinar, discutindo o caso clínico e auxiliando na tomada de decisões e na escolha das condutas. 
Tabela 5. Dados clínicos dos pacientes que evoluíram à óbito $(\mathrm{n}=55)$.

\begin{tabular}{lcc}
\hline Variáveis & $\mathbf{N}^{\mathbf{0}}$ & $\%$ \\
\hline Diagnóstico Inicial & 13 & 23,64 \\
TCE (somente) & 11 & 20,00 \\
TCE + Trauma torácico e/ou abdominal + Fratura de Membros & 8 & 14,55 \\
Trauma torácico e/ou abdominal & 3 & 5,45 \\
TCE + Trauma torácico e/ou abdominal & 3 & 5,45 \\
TCE + Fratura de Membros & 3 & 5,45 \\
TCE + Fratura de Coluna & 8 & 14,55 \\
Trauma torácico e/ou abdominal + Fratura de Membros & 6 & 10,91 \\
Enforcamento ou intoxicação exógena (suicídio) & 6 \\
\hline
\end{tabular}

Fonte: Autoria própria (2022).

Dos 297 pacientes admitidos no ano de 2020 na sala de emergência do HUOP, 254 (85,52\%) receberam atendimento da equipe de fisioterapia. No período de coleta dos dados, o HUOP não dispunha de atendimento fisioterapêutico no período noturno. Os 43 pacientes $(14,48 \%)$ cujos prontuários não possuíam informações da equipe de fisioterapia, foram relativos à casos admitidos no período noturno e que evoluíram à óbito nas primeiras horas, ou por imediatamente após à admissão já serem encaminhados emergencialmente para o centro cirúrgico ou transferidos para um leito de UTI.

As condutas desempenhadas pelo serviço de fisioterapia, baseiam-se na necessidade de cada paciente. Destes 254 pacientes atendidos, em 17 deles $(6,69 \%)$ foi realizado somente a participação da fisioterapia no processo de admissão, que consiste na avaliação inicial no paciente, na titulação da oxigenioterapia e também na preparação e ajuste da ventilação mecânica invasiva. Os demais, além da avaliação inicial, do controle ventilatório, ajuste de parâmetros de VMI (quando faziam utilização de VMI) e titulação da oxigenioterapia, realizaram condutas fisioterapêuticas específicas e, quando necessário, foi realizado também a aspiração de vias aéreas, sendo que 96 (37,80\%) necessitaram das condutas de fisioterapia respiratória seguida do procedimento de aspiração de vias aéreas superiores, 80 (31,50\%) receberam atendimento com fisioterapia motora e respiratória seguida de aspiração de vias aéreas superiores e 61 (24,02\%) tiveram como conduta fisioterapia motora e respiratória sem necessidade de aspiração (Tabela 6).

Tabela 6. Dados sobre o atendimento fisioterapêutico em pacientes vítimas de trauma atendidos na sala de emergência do Hospital Universitário do Oeste do Paraná (n=297).

\begin{tabular}{lll}
\hline Variáveis & N & $\%$ \\
\hline Foi atendido pela Fisioterapia & 254 & 85,52 \\
Sim & 43 & 14,48 \\
Não & 17 & 6,69 \\
\hline Condutas Fisioterapêuticas & 96 & 37,80 \\
Participação somente na admissão do paciente & 80 & 31,50 \\
Fisioterapia respiratória + aspiração & 61 & 24,02 \\
Fisioterapia respiratória + motora + aspiração & \\
Fisioterapia motora + respiratória & & \\
\hline
\end{tabular}

Fonte: Autoria própria (2022).

Como consequência do trauma, podem surgir alterações motoras e/ou complicações respiratórias e as condutas fisioterapêuticas são definidas de acordo com o quadro clínico de cada paciente. Padovani et al. (2017), afirmam que a 
fisioterapia motora precoce nos casos dos pacientes politraumatizados críticos, é de extrema necessidade, auxiliando na reabilitação motora, além da manutenção da mobilização articular global e treinamento muscular.

Para Werle et al. (2019) e Duarte et al. (2020), a admissão na emergência se dá principalmente pelas alterações pulmonares e cardiovasculares, desta forma a fisioterapia respiratória desempenha um papel importante no acompanhamento e na evolução destes pacientes, atuando principalmente na prevenção e/ou no tratamento das complicações respiratórias, com condutas que visam a higiene brônquica e a expansão pulmonar. A fisioterapia respiratória utiliza inúmeras técnicas e recursos que auxiliam na mecânica pulmonar, e os exercícios propostos pelo fisioterapeuta têm como intuito principal a manutenção da musculatura respiratória aumentando assim a ventilação pulmonar. Com a utilização das técnicas e condutas adequadas, podese reduzir a necessidade de intubação orotraqueal, além de diminuir o tempo de internação hospitalar e a mortalidade

\section{Conclusão}

Os pacientes vítimas de trauma admitidos na urgência e emergência de um Hospital Universitário, foram, em maioria, do sexo masculino e com maior prevalência no diagnóstico de TCE, seja isolado ou associado a outros traumas e a maioria dos pacientes vítimas de trauma necessitaram de internação em unidades de cuidados intensivos, o que reforça a gravidade destes pacientes. A mortalidade foi maior nos pacientes com trauma torácico ou abdominal, principalmente com fratura de membros e/ou TCE associados. Quanto ao desfecho final do paciente, a maioria dos pacientes teve uma evolução satisfatória, obtendo a alta hospitalar. Porém não pôde ser observado possíveis sequelas decorrentes do trauma por se tratar de um estudo retrospectivo.

Em relação a fisioterapia, pelo número elevado de pacientes politraumatizados com necessidade de ventilação mecânica, observou-se principalmente condutas com ênfase nos protocolos respiratórios, seja ela no ajuste e manejo ventilatório, na utilização de técnicas especificas e a na necessidade de aspiração de vias aérea superior. Sendo assim os dados do estudo podem auxiliar na admissão e no manejo deste perfil de pacientes na urgência e emergência, além de ressaltar a importância do profissional fisioterapeuta junto a equipe multidisciplinar.

Sugere-se para estudos futuros que sejam avaliados os prontuários dos pacientes diagnosticados com TCE leve e grave separadamente, para assim observar criteriosamente a influência da gravidade do TCE no prognóstico do paciente, seja ele associado ou não a outros traumas.

\section{Referências}

Almeida, I. C. N., Lima, G. M., Costa, L. A., Carneiro, L. M., Santos, M. I. G., Macêdo, R. C., \& Costa, L. R. N., (2017). Atuação da fisioterapia na urgência e emergência de um hospital referência em trauma e queimados de alta e média complexidade. Revista da Universidade Vale do Rio Verde, 15(1) 791-805.

Araujo, D. D., \& Araujo, J. E. S. (2020). Rotina de cuidados ao paciente politraumatizado em unidade de terapia intensiva. (Tese de Doutorado). Centro Universitário Fametro, Fortaleza, Brasil.

Azevedo Filho, H. R. C. (2021). Reminicências do antigo Hospital do Pronto Socorro do Recife: Primeiro contato com a Morte Encefálica. Jornal Memorial da Medicina, 3(2), 42-47.

Duarte, M. P., Dalla Rosa, L. L., Pinheiro, E. M., Alves, I. K., Santos, A. A., de Andrade, Á. D. B., \& Diniz, W. A. (2020). Influência da fisioterapia na reabilitação de pacientes submetidos à drenagem torácica em um hospital de urgência e emergência da amazônia legal. Revista Eletrônica Acervo Saúde, (45), e2959-e2959.

Gomes, A. T. D. L., Alves, K. Y. A., Bezerril, M. D. S., Rodrigues, C. C. F. M., Ferreira, M. A., \& Santos, V. E. P. (2018). Validation of graphic protocols to evaluate the safety of polytrauma patients. Acta Paulista de Enfermagem, 31, 504-517.

Gomes, A. T. L. G., Silva, M. F., Dantas, B. A. S., Dantas, R. A. N., Mendonça, A. E. O., \& Torres, G. V. (2017) Perfil epidemiológico das emergências traumáticas assistidas por um serviço pré-hospitalar móvel de urgência. Enferm Glob 2017, 45 (2).

Gonçalves, A. C. S., (2019). Perfil clínico dos pacientes atendidos pelo serviço de fisioterapia na unidade de urgência e emergência de um hospital público de Minas Gerais. Cardiorespiratory Physiotherapy, Critical Care and Rehabilitation, 5(3), 55-62. 
Lentsck, M. H., Sato, A. P. S., \& Mathias, T. A. F. (2019). Panorama epidemiológico de dezoito anos de internações por trauma em UTI no Brasil. Revista de Saúde Pública, 53.

Machado, T., Figueiredo, C. M. B., Gomes-Ferreira, P. H. S., Hergesel de Oliva, A., Melo, Melo-Netto, F. M., Faverani, L. P., \& Souza, F. A. (2018). Politrauma decorrente de acidente motociclístico-relato de caso. Archives of health investigation, 7.

Ministério da Saúde. (2013). Agência Nacional de Vigilância Sanitária. Resolução - RDC n. 36, de 25 de julho de 2013 . Institui ações para a segurança do paciente em serviços e saúde e dá outras providências. Brasília (DF): Diário Oficial da União. https://bvsms.saude.gov.br/bvs/saudelegis/anvisa/2013/rdc0036_25_07_2013.pdf

Ministério da Saúde. (2015). Saúde Brasil 2014: uma análise da situação de saúde e das causas externas. Brasília (DF): https://bvsms.saude.gov.br/bvs/publicacoes/saude_brasil_2014_analise_situacao.pdf

Ministério da Saúde. (2019). Saúde Brasil 2018: Uma análise da situação de saúde e das doenças e agravos crônicos: desafios e perspectivas. Recuperado de. https://bvsms.saude.gov.br/bvs/publicacoes/saude_brasil_2018_analise_situacao_saude_doencas_agravos_cronicos_desafios_perspectivas.pdf

Moura, A., Carvalho, J. G., \& Silva, M. A. B. (2018). Urgência e emergência: conceitos e atualidades. Saúde \& Conhecimento - Jornal de Medicina Univag, $12-18$.

Padovani, C., Silva, J. M., \& Tanaka, C. (2017) Fisioterapia nos pacientes politraumatizados graves: modelo de assistência terapêutica. 5403.

Paixão, T. C. R. D., Campanharo, C. R. V., Lopes, M. C. B. T., Okuno, M. F. P., \& Batista, R. E. A. (2015). Nursing staff sizing in the emergency room of a university hospital. Revista da Escola de Enfermagem da USP, 49(3), 481-487.

Pimentel, S. K., Sawczyn, G. V., Mazepa, M. M., Rosa, F. G. G. D., Nars, A., \& Collaço, I. A. (2015). Fatores de risco para óbito no trauma abdominal fechado com abordagem cirúrgica. Revista do Colégio Brasileiro de Cirurgiões, 42, 259-264.

Rezende Neta, D. S., Alves, A. K., Leão, G. D. M., \& Araújo, A. A. D. (2012). Perfil das ocorrências de politrauma em condutores motociclísticos atendidos pelo SAMU de Teresina-PI. Revista Brasileira de Enfermagem, 65, 936-941.

Santos, G. A., Cesar, A. L. M., Santos, F. J. M. M., Tunel, F. M. S., Todt, G. D., de Andrade Souza, I. J., \& José, W. (2021). Abordagens clínicas associadas ao atendimento inicial do paciente politraumatizado: Revisão de literatura. Research, Society and Development, 10(1), e7210111530-e7210111530.

Schossler, D. (2019). Perfil epidemiológico de pacientes politraumatizados atendidos em uma Unidade e Terapia Intensiva adulto no interior do Rio Grande do Sul. Biblioteca Digital da Univates. http://hdl.handle.net/10737/2386

Silva, E., Rodrigues, F. A., \& Lima, R. S., (2014) Caracterização das vítimas de trauma atendidas pelo sistema privado de resgate especializado em atendimento pré-hospitalar. Meridiano 47-Journal of Global Studies, 5(3), 949-960.

Silva, L. A. P., Ferreira, A. C., Paulino, R. E. S., de Oliveira Guedes, G., da Cunha, M. E. B., Peixoto, V. T. C. P., \& Faria, T. A. (2017). Análise retrospectiva da prevalência e do perfil epidemiológico dos pacientes vítimas de trauma em um hospital secundário. Revista de Medicina, 96(4), $245-253$.

Sousa, K. H. J. F., Damasceno, C. K. C. S., Almeida, C. A. P. L., Magalhães, J. M., \& Ferreira, M. D. A. (2019). Humanização nos serviços de urgência e emergência: contribuições para o cuidado de enfermagem. Revista Gaúcha de Enfermagem, 40.

Dados estatísticos. (2012). Universidade Estadual do Oeste do Paraná (2020). Dados Estatísticos. https://www.unioeste.br/portal/institucional-huop/dados$\underline{\text { estatisticos }}$

Vieira, S., \& Hossne, W. S. (2021). Metodologia cientifica para a área da saúde (3a ed.). Guanabara Koogan.

Werle, R. W., Kutchak, F., Piccoli, A., \& de Mello Rieder, M. (2019). Indicações para inserção do profissional fisioterapeuta em uma unidade de emergência. Cardiorespiratory Physiotherapy, Critical Care and Rehabilitation, 4(1), 33-41.

Will, R. C., Farias, R. G., Jesus, H. P., \& Rosa, T. (2020). Cuidados de enfermagem aos pacientes politraumatizados atendidos na emergência. Nursing, 23(263), 3766-3777. 